\title{
Performance Limits of Three-Phase Self-Excited Induction Generator (SEIG) as a Stand Alone DER
}

\author{
Marwa Ben Slimene* and Mohamed Arbi Khlifi ${ }^{\dagger}$
}

\begin{abstract}
This paper present a unified method of steady state performance analysis and limits characteristics of an autonomous three-phase self-excited induction generator (SEIG) driven by a wind turbine under different types of loads and speeds. The proposed method is based on a new mathematical function to solve for the real and imaginary components of the complex equation of the mathematical model. Performances limits, regulation and characteristics of different configurations will be thoroughly examined and compared. The proposed system will be modeled and simulated and the performance limits characteristics will be compared with variable speed and variable capacity.
\end{abstract}

Keywords: Three-phase induction generator, Performances limits, Regulation, Self-Excited, Distributed Energy Resources (DER)

\section{Introduction}

Energy is the gift of nature to the mankind in various forms. With ever increasing population, improvement in the living standard of the people, industrialization of the developing countries, the worldwide demand for energy is expected to enhance rather considerably in the near future. The primary source of energy is fossil fuel, however the depletion of fossil fuel reserves and environmental degradation caused by their widespread use, particularly global warming, urban air pollution, strongly suggests that the use of non-conventional, renewable and environmental friendly energy resources is vital for directing the global energy supplies towards a sustainable path. [1-2].

The growing importance on decentralized power generation has led to the development of standalone power generation. Self-excited induction generators have been increasingly used in isolated power system such as wind energy and hydropower system [3-4]. The SEIG has advantages such as brushless construction (squirrel cage rotor), absence of dc power supply for excitation, absence of synchronizing equipment, reduced size, good over-speed capability, reduced maintenance cost, inherent short-circuit protection capability and better transient performance. [5-6]. In the past three decades, considerable development has taken place in the design and operation of variable speed stand-alone systems using self-excited induction generators (SEIGs), in view of their known advantages over other types of generators. It is known that the magnitude and frequency of the output voltage of the

$\dagger$ Corresponding Author: Dept. of Electrical Engineering, College of Engineering, University of Hail, Saudi Arabia. (me.khlifi@uoh.edu.sa)

* Dept. of Electrical Engineering, National School of Engineering of Tunis ENSIT, University of Tunis, TUNISIA. Research Laboratory SIME, ENSIT

Received: May 14, 2016; Accepted: July 13, 2016 generators vary with the driving speed and load and this output power can be used directly for certain frequency insensitive loads only. [7].

Self-excited induction generators (SEIG) have found applications in autonomous power generation, particularly using renewable energy. Despite the simplicity of the hardware, requiring only squirrel-cage induction machines and capacitors banks, the analysis of their operation is quite challenging. This is due, in part, to the generators working in the saturated magnetic regime. In most cases, researchers have only investigated steady-state characteristics with pure resistive loads [8-9]. Induction generators are being increasingly used in wind energy electric conversion systems, both for grid connected operation and for isolated power supplies.

The most typical analytical approach is based on the steady-state per-phase equivalent circuit of the induction machine. A necessary condition for the existence of a nonzero operating point is obtained by equating to zero either the total loop impedance or the total node admittance at the magnetizing branch [10-11]. For resistive-inductive loads, self-excitation conditions and steady-state values have been obtained by solving iteratively or numerically systems of two polynomial equations giving the frequency, and either the mutual inductance or the capacitance.

The stand-alone SEIG is basically an induction machine which is driven by a prime mover, while an external capacitor is connected across its stator terminals. The capacitor is required to build the air-gap flux, and to provide any lagging reactive power demand of the load. The majority of the SEIG load in remote area usually enriches with both static and dynamic loads. Although considerable research works have been reported on various aspects of the SEIG, it is largely limited to application of the SEIG feeding static loads. 


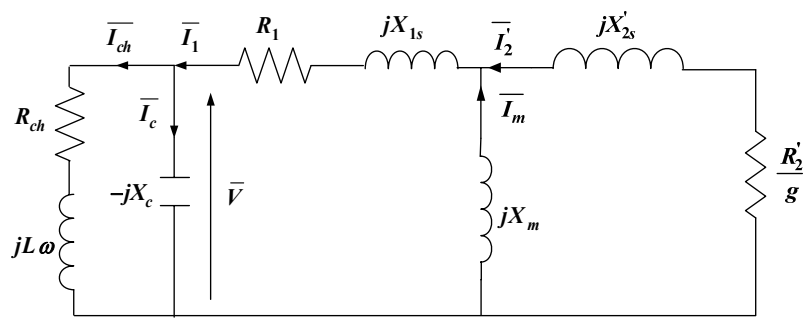

Fig. 1. Diagram per phase of a self-excited induction generator with load

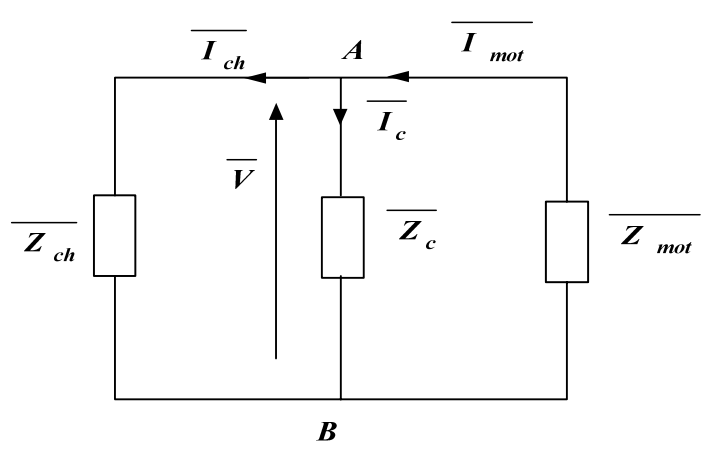

Fig. 2. Simplified equivalent scheme of a stand-alone induction generator.

\subsection{Equivalent electrical circuit of induction machine}

In stationary reference frame the dynamic machine model can be derived by substituting we $=0$ in synchronously rotating reference frame $\mathrm{d}-\mathrm{q}$ model equations. The $\mathrm{d}-\mathrm{q}$ axes equivalent circuit of a (SEIG) supplying an inductive load is shown in Fig. (1).

By applying the law of the nodes in A, we find:

$$
\bar{I}_{m o t}=\bar{I}_{c}+\bar{I}_{c h}
$$

With

$$
\begin{gathered}
\bar{I}_{c}=\frac{\bar{V}}{Z_{c}}=\bar{V}_{\bar{Y}} \text { and } \bar{Y}_{c h}=\frac{1}{Z_{c}} \\
\bar{I}_{m o t}=\frac{\bar{V}}{\bar{Z}_{m o t}}=-\bar{V} \bar{Y}_{m o t} \\
\bar{I}_{c h}=\frac{\bar{V}}{\bar{Z}_{c h}} \bar{V}_{\text {mot }} \text { and } \bar{Y}_{c h}=\frac{1}{Z_{c h}}
\end{gathered}
$$

Eq. (3) becomes:

$$
\begin{aligned}
& -\bar{V} \bar{Y}_{m o t}=\bar{V}_{\bar{Y}}+\bar{V} \bar{Y}_{c h} \\
& \bar{V}\left(\bar{Y}_{m o t}+\bar{Y}_{c}+\bar{Y}_{c h}\right)=0
\end{aligned}
$$

As $\mathrm{V} \# 0$ then

$$
\left(\bar{Y}_{m o t}+\bar{Y}_{c}+\bar{Y}_{c h}\right)=0
$$

On the other hand, the equivalent impedance of the motor phase is given by Eq. (8).

$$
Z_{m o t}=R_{1}+j l_{1} w+\frac{j L_{m} w\left(j l_{2}+\frac{R_{2} w}{w-w_{s}}\right)}{j w\left(L_{m}+l_{2}\right)+\frac{R_{2} w}{w-w_{s}}}
$$

This equation can be turned on:

$$
\begin{aligned}
& \bar{Z}_{\text {mot }}=\frac{a+j b}{R_{2}+j\left(w-w_{e}\right) L} \\
& \bar{Y}_{\text {mot }}=\frac{R_{2}+j\left(w-w_{e}\right) L}{a+j b}
\end{aligned}
$$

Otherwise,

$$
\begin{gathered}
\bar{Y}_{c}=\frac{1}{\bar{Z}_{c}}=j c w \\
\bar{Y}_{c h}=\frac{1}{\bar{Z}_{c h}}=\frac{1}{R+j l w}
\end{gathered}
$$

Eq. (7) is satisfied if and only if the real part and the imaginary part of the resultant admittance is zero then deduced:

$$
\left\{\begin{array}{l}
R_{e}\left(\bar{Y}_{m o t}+\bar{Y}_{c}+\bar{Y}_{c h}\right)=0 \\
I_{m}\left(\bar{Y}_{m o t}+\bar{Y}_{c}+\bar{Y}_{c h}\right)=0
\end{array}\right.
$$

It is relatively easy to write (13) in the form of polynomials and solve the system. Thus, one obtains a system of two equations and two unknowns.

$$
\begin{gathered}
\left\{\begin{array}{l}
R_{e}\left(\bar{Y}_{m o t}+\bar{Y}_{c}+\bar{Y}_{c h}\right)=0 \\
I_{m}\left(\bar{Y}_{m o t}+\bar{Y}_{c}+\bar{Y}_{c h}\right)=0
\end{array}\right. \\
\left\{\begin{array}{l}
a_{4} w^{4}+a_{3} w^{3}+a_{2} w^{2}+a_{1} w+a_{0}=0 \\
b_{3} w^{3}+b_{2} w^{2}+b_{1} w+b_{0}=0
\end{array}\right.
\end{gathered}
$$

By replacing the coefficients by their expressions, we deduce the expression of the mutual inductance.

$$
L_{m}=\frac{-\left(b_{32} w^{3}+b_{22} w^{2}+b_{12} w+b_{02}\right)}{b_{31} w^{3}+b_{21} w^{2}+b_{11} w+b_{01}}
$$

Similarly by substituting the coefficients by their expressions in the first equation of the system (15) and use (16) is obtained a polynomial of order 7.

$P_{7} w^{7}+P_{6} w^{6}+P_{5} w^{5}+P_{4} w^{4}+P_{3} w^{3}+P_{2} w^{2}+P_{1} w+P_{0}$ For a capacity of excitation and a rotational speed data, it is possible to solve the above system. The resolution of the polynomial, used to deduce the pulsation. This gives $L_{m}$ as 
from (16) and is used to calculate all the electrical quantities.

According to the characteristic $\phi=f\left(L_{m}\right)$ obtained by the test performed on the vacuum machine, the flow $\phi$ in function of the inductance $L_{m}$ is approximated by a straight line described by:

$$
\phi=k_{1}-k_{2} L_{m}
$$

\section{Performance limits of SEIG}

The fixed excitation capacitance is selected as $9 \mu \mathrm{F}$, for the $1 \mathrm{~kW}$ induction machine data is given annexes. The SEIG driven by wind turbine with wind velocity of 12.6 $\mathrm{m} / \mathrm{s}$ at no load and the performances limits results are shown in Figures blew. It is observed that the residual magnetism taken in terms of volt for the simulation induces a voltage across the self-exciting capacitor and produces a capacitive current or a lagging magnetizing current in the stator winding and result a higher voltage. This procedure goes on until the saturation of the magnetic field occurs as observed in the simulation results shown in the presented results.

\subsection{Limits without load}

\subsubsection{Limits of characteristic $V=f(C)$}

In the autonomous running voltage is not required, so the power limits of the asynchronous machine are defined by the nominal quantities such as the rated current and voltage, which are indicated on the rating plate of the machine.

For a given value of the rotational speed, the voltage is sensitive to the variation of the capacity $\mathrm{V}=84.1 \mathrm{~V}$. Note that the machine boots from a capacity corresponding to a voltage $\mathrm{V}=84.1 \mathrm{~V}$. The nominal voltage of the machine $\mathrm{V}=220 \mathrm{~V}$ is obtained for a capacitor denoted $C_{\max }$ with $C_{\max }=14.95 \mu \mathrm{F}$. Increasing the excitation capacity above causes an increase of the voltage to the stator which can burn the machine, thus generator voltage admits limited

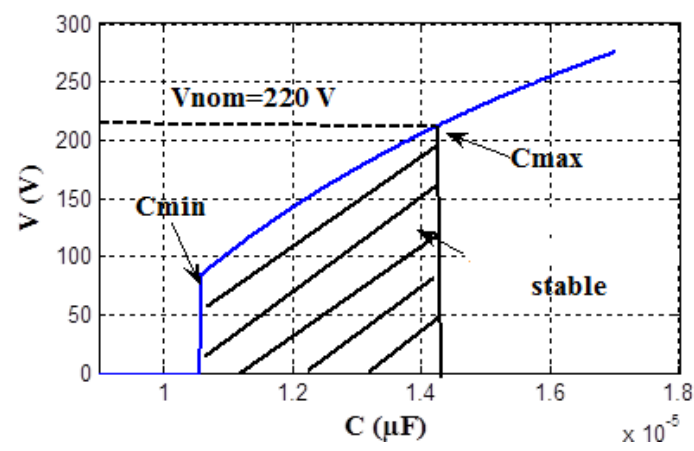

Fig. 3. Stable operating zone of generator voltage from the characteristic with: $C_{\min }=10.59 \mu F, C_{\max }=14.59 \mu F$ performance. For a given speed two critical values of capacitance are found, the first is the seed of the generator and the second to the rated voltage. In general, the capacitance value should be greater than the capacity to ensure starting of the generator and should be chosen such that the voltage developed by the generator does not exceed its rated value. So the stable operation of the selfexcited induction generator voltage is ensured if the following condition is satisfied $C_{\min } \leq C \leq C_{\max }$.

To show the effect of speed on the operating limits of the generator self-excited, we have performed simulations for

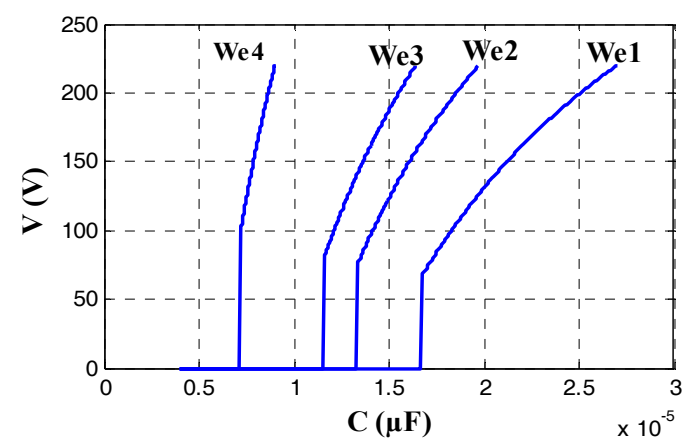

Fig. 4. Load voltage according to the capacity for different speeds without exceeding the rated voltage

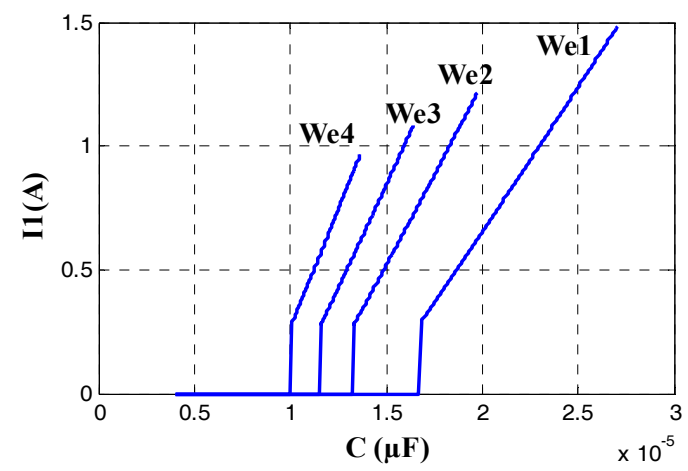

Fig. 5. Stator current variation with variable speed capacity with: $250 \mathrm{rad} / \mathrm{s} \leq w_{e} \leq 322 \mathrm{rad} / \mathrm{s}$.
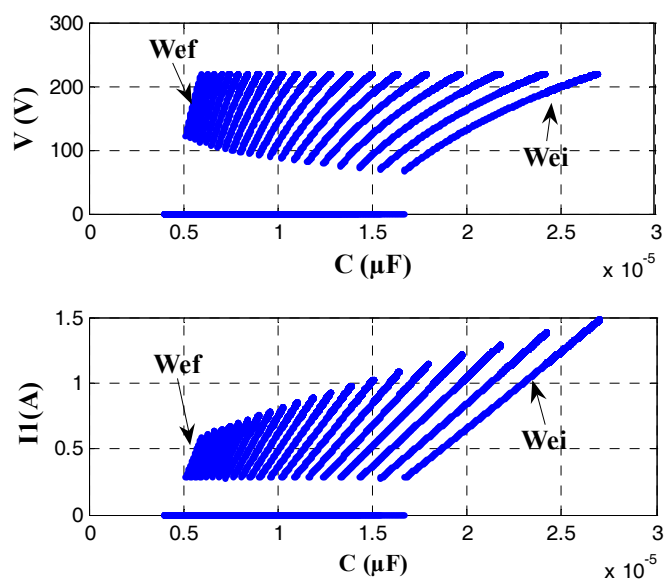

Fig. 6. Load voltage and stator current with variable speed 
different speed values.

The extreme values of the capacity depend on the variation of the speed. Indeed, the increase in the speed of rotation leads to reducing the range of variation of the capacity, Figs. 4 and 5.

The representation of the characteristic $V=f(c)$ at different speeds in two dimensions is not previewed booting strong velocity values so we made use of the threedimensional representation.

As speed increases, the boot capacity values decreases and even the one corresponding to the nominal voltage. So for high rotation speeds, the stable operation range of the terminal voltage is reduced.

\subsubsection{Limits of characteristic of $V=f(w e)$}

A given capacity, voltage depends on the variation of the speed, the machine boots from a rated speed $w_{e \min }=$ $280.84 \mathrm{rad} / \mathrm{s}$ corresponding to a voltage $\mathrm{V}=84.1 \mathrm{~V}$, Fig. 8 . The rated voltage of the machine $\mathrm{V}=220 \mathrm{~V}$ is obtained for a rated speed as $w_{e \max }=335 \mathrm{rad} / \mathrm{s}$.

For a speed values greater than the voltage is a large lead to overheating and can damage the insulation of the machine. Therefore, the value of the speed must be chosen carefully. Knowing the speed of the extreme values that help to define the stable operating zone of the generator

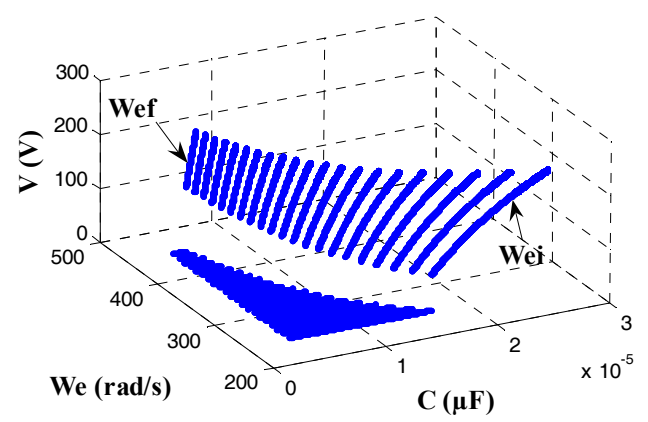

Fig. 7. Three-dimensional graph of variable speed without exceeding the rated voltage

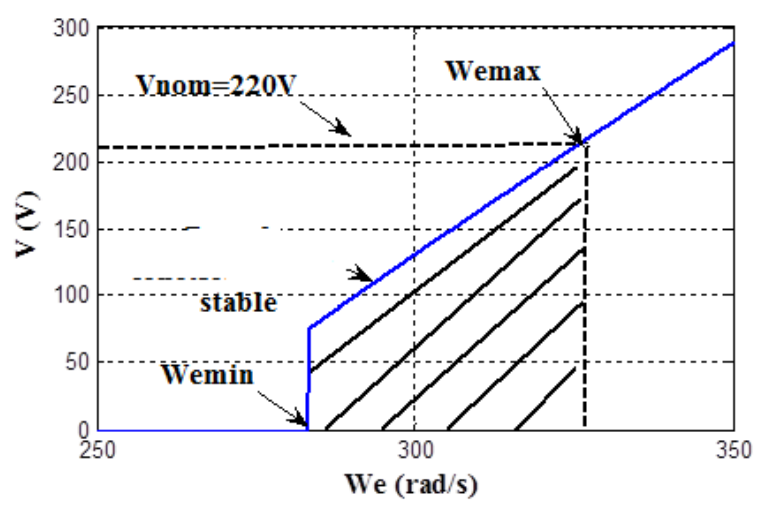

Fig. 8. Operation area of the generator voltage from the characteristic $V=f\left(w_{e}\right)$ with constant capacity $w_{e \min }=280.84 \mathrm{rad} / \mathrm{s}, w_{e \max }=335 \mathrm{rad} / \mathrm{s}$ to self-excited induction, thus given capacity, the stable operating range of the generator is expressed by $\left(w_{\min } \leq w_{e} \leq w_{\max }\right)$. The excitement ability to affect the operating limits of the self-excited generator is shown in Figs. (9) and (10). Hence we retain the ability to believe that when the generator starts faster and current corresponding to the rated voltage increases.

Load in critical speed values depending on the excitation capacity, provided that the voltage to the stator does not exceed its rated value. Figs. 11 and 12 illustrate the performance of the vacuum generator independent in terms of voltage and current that can be generated without exceeding the limit of the stator voltage.

The generator starts at low speeds and with low starting voltage when the excitation capacity increases. On the other hand, the current corresponding to the rated voltage is important Figs. 11 and 12.

Indeed, the increase in the excitation power causes an increase of the stable operating range of the terminal voltage independent, so it is particularly interested in operation at high values of the excitation capacity.

\subsection{Limits with load}

The terminal voltage of the machine is more important it is seen that vacuum. In addition, when the load is lowered

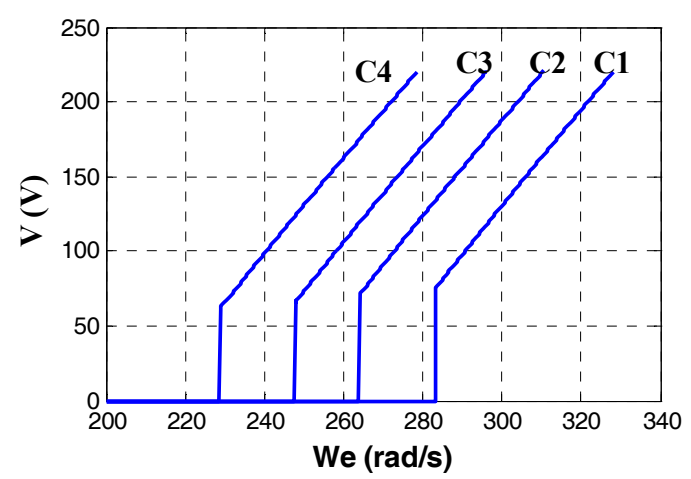

Fig. 9. Load voltage according to the speed with variable capacities $C_{1}=13 \mu F, C_{2}=15 \mu F, C_{3}=17 \mu F, C_{4}=$ $20 \mu F$

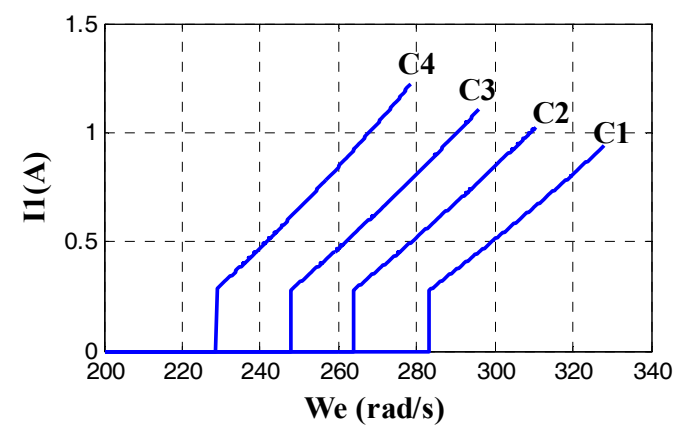

Fig. 10. Stator current with variable capacity $C_{1}=13 \mu \mathrm{F}$, $C_{2}=15 \mu F, C_{3}=17 \mu F, C_{4}=20 \mu F$ 


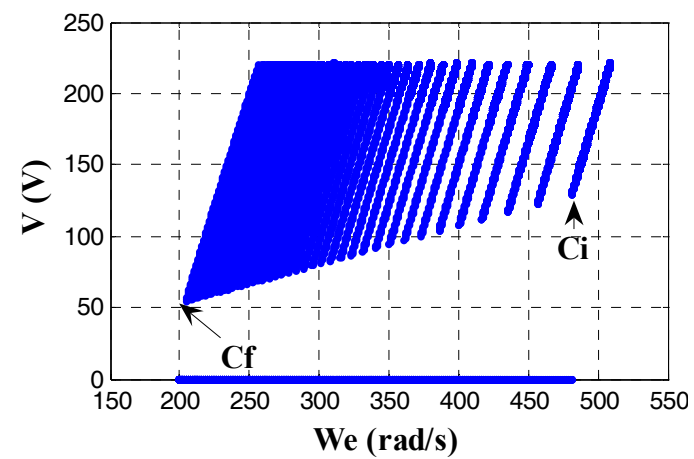

Fig. 11. Load voltage according to the variable speed capacity $C_{1}=4.5 \mu F, C_{2}=25 \mu F, \Delta C=0.5 \mu F$

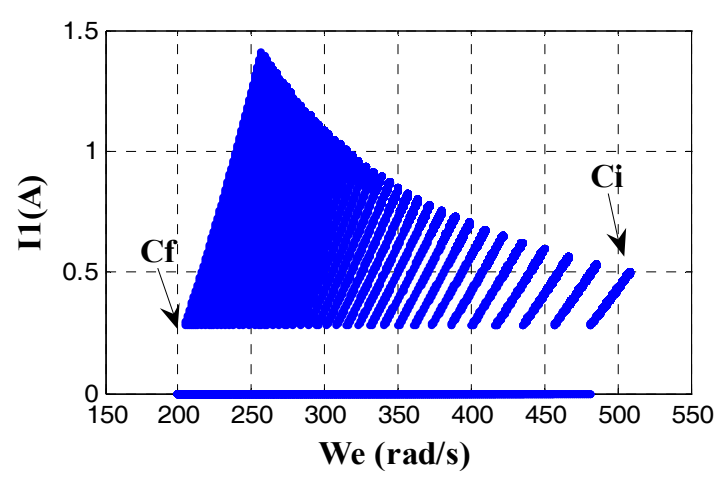

Fig. 12. Stator current and speed for different capacities $C_{1}=4.5 \mu F, C_{2}=25 \mu F, \Delta C=0.5 \mu F$

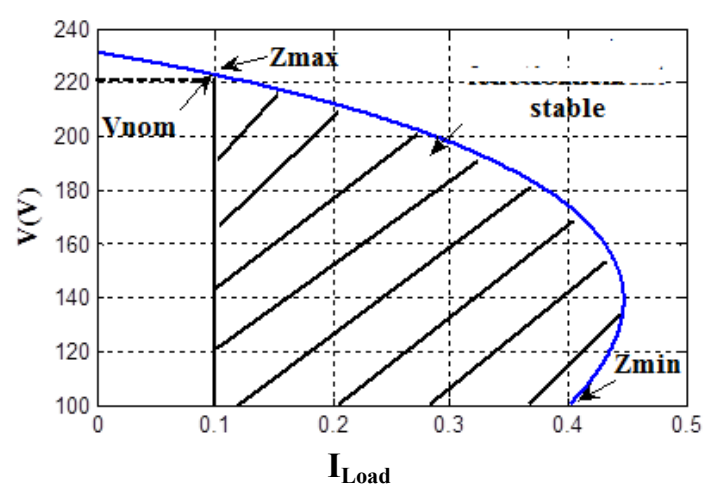

Fig. 13. Stable operation area of the induction generator supported for $C=15 \mu F$ and $Z_{\max }=1083.7 \Omega$ and $Z_{\text {min }}=301.8 \Omega$

the voltage drop and the load current increases to a maximum value, then the current and voltage decrease sets to tend to zero, Fig. 13.

There is a maximum value of the impedance of the rated load above which is beyond the nominal operating conditions of the generator. Accordingly, there is a limit value of the rated load impedance $Z_{\text {min }}$ below which the excitation of the machine will be lost. This defines a load range which ensures stable operation of the generator. Definitely, the choice of the impedance of the load must

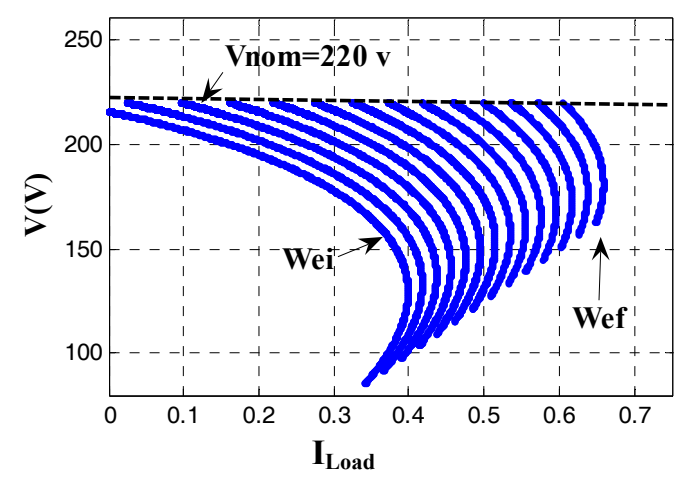

Fig. 14. Characteristics of terminal voltage with different speeds $w_{e i}=309 \mathrm{rad} / \mathrm{s}, w_{e f}=335 \mathrm{rad} / \mathrm{s}$

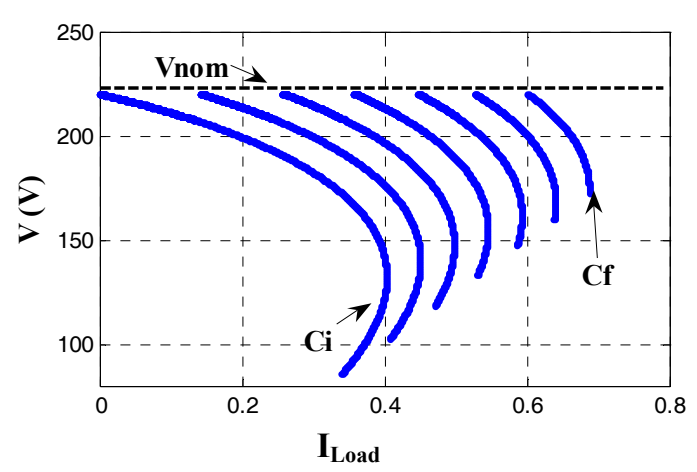

Fig. 15. Characteristics of terminal voltage with different capacity $C_{i}=14 \mu F, C_{f}=18 \mu F, \Delta C=0.3 \mu F$

meet the following condition $Z_{\text {min }} \leq Z_{c h} \leq Z_{\max }$.

\subsubsection{Characteristic of $V=f\left(I_{\text {Load }}\right)$ with different speeds}

The preliminary study of the autonomous asynchronous generator has shown that the terminal voltage is responsive to the excitation capacity, the drive speed as well as the impedance of the load. In the following section, the performance of the machine is analyzed when the excitation capacity is fixed while the other two are considered variables.

Increasing the fixed rotational speed capacity generates the shift characteristics of the voltage depending on the load current and the extreme values of the load impedance decreases, Fig. 14. Indeed, it decreases the range of variation of the load and consequently the reduction of the stable operating range of the generator load.

\subsubsection{Characteristic $V=f\left(I_{\text {Load }}\right)$ for different capacities}

By setting the speed, the load of the voltage depends on the capacitance value and the load impedance, Fig. 15.

For a given speed of rotation, if one increases the excitation power characteristic of the voltage as a function of the load current flows and the maximum load impedance decreases. Follows the load variation range decreases and thus the stable operation region of the generator load to large values of the capacity reduces. 


\section{Conclusion}

In this paper, a critical analysis was presented to establish the performance limits of an isolated induction generator unregulated empty and supported. We have shown that the operating points are variable and depend on the excitation capacity so that the driving speeds. The results show that the priming ability of the values increased significantly with the decrease in speed. The analysis was also used to predict the minimum values of the capacity and speed required for the initiation of the vacuum generator. By imposing the rated voltage of the generator as a limit possible to determine the maximum values of capacity and speed. The study of the impact of the load voltage and the stator current and the pulsation showed the performance limits of the self-excited generator induction. Indeed, for this mode of operation, there are two problems, the voltage drop and the pulse fall.

\section{Acknowledgements}

The authors would like to thank the Deanship of the Scientific Research of university of hail, Saudi Arabia for funding and supporting this research project (0150376 -EE 2016).

\section{References}

[1] Feifei Bu. "Wide-Speed-Range-Operation Dual StatorWinding Induction Generator DC Generating System for Wind Power Applications", IEEE Transactions on Power Electronics, 30, 230-241. 2015.

[2] Marwa B S, Mohamed A K, Mouldi B F, Habib R, "Modeling of Dual Stator Induction Generator with and Without cross Saturation", Journal of Magnetics, 20 1505-1521. 2015.

[3] M. Ben Slimene, M. A. Khlifi, M. Benfredj, H. Rehaoulia, "Analysis of Saturated Self-Excited Dual Stator Induction Generator for Wind Energy Generation", Journal of Circuits, Systems, and Computers 24, 1450169. 2015.

[4] Mohamed Arbi Khlifi. Badr. S "Steady State Analysis of an Isolated Self-Excited Dual Three-Phase Induction Generator for Renewable Energy", International Journal of Modern Nonlinear Theory and Application, 3 191-198. 2014.

[5] Marwa B S, Mohamed A K, Mouldi B F, Habib R, "Effect of the Stator Mutual Leakage Reactance of Dual Stator Induction Generator", International Journal of Electrical Energy, 2 1810-1818. 2014.

[6] Singh, G. K. Modeling and experimental analysis of a self-excited induction generator for stand-alone renewable energy generation. Renewable Energy; 33 1605-1621. 2008.
[7] Singh, G. K. Senthil Kumar, A. Saini, R. P. A selfexcited induction generator for stand-alone renewable energy generation: experimental analysis. European Transactions on Electrical Power; 20 884-900. 2010.

[8] Singh, G. K. Senthil, K. A. Saini, R. P. Performance analysis of a simple shunt and series compensated selfexcited induction generator for stand-alone renewable energy generation", Energy Conversion and Management; 52 1688-1699. 2011.

[9] Marwa B S, Mohamed A K, Mouldi B F, Habib R, "The process of self-excitation in Dual Three-Phase induction generator" International Review of Electrical Engineering (IREE). 8 1957-1962. 2013.

[10] Mohamed A. K, Marwa B. S, Mouldi B. F and Habib R. Performance Evaluation of Self-Excited DSIG as a Stand-alone Distributed Energy Resource", Springer: Electrical Engineering, 97 261-345. 2016.

[11] L. Wang and D.-J. Lee, Coordination control of an AC-to-DC converter and a switched excitation capacitor bank for an autonomous self-excited induction generator in renewable-energy systems, IEEE Trans. Indus. Appl. 50 2828-2836. 2014.

Marwa Ben Slimene was born in Tunisia, in 1988. He received the M.S., and Ph.D. in Electrical Engineering from the National College of Engineering of Tunis ENSIT, Tunisia. He is research laboratory SIME in the University of Tunis. His main interest research areas are renewable energy, power electronics and control of industrial drives.

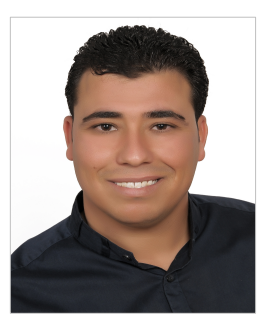

Mohamed Arbi KHLIFI was born in Tunisia, in 1982. He received the M.S., and Ph.D. in Electrical Engineering from the Tunisian National University, Tunisia. He joined the National college of Engineering of Tunis, as Professor in the Department of Electrical Engineering. He is currently a Professor in the Electrical Engineering Department, College of Engineering, hail University. Prof. KHLIFI has published More than 50 research papers in many journals and international conferences. He has organized many national and international conferences and has been member of the international Board committee of many International Conferences, JTEA, MELECON, ICESA, IREC... His is Associate Editor of IJECEE journal. His main is member IEEE and ASET (association for Tunisian electrical specialists). He is research laboratory in Signal Image and Energy Mastery in the University of Tunis. His main interest research areas are renewable energy, wind, solar, and control of high efficiency integrated electric energy conversion in various industrial fields. Power electronics and control of industrial drives. 